Article

\title{
Polyion Complex Vesicles with Solvated Phosphobetaine Shells Formed from Oppositely Charged Diblock Copolymers
}

\author{
Keita Nakai ${ }^{1}$, Kazuhiko Ishihara ${ }^{2}$, Michael Kappl ${ }^{3}$, Syuji Fujii ${ }^{4}$, Yoshinobu Nakamura ${ }^{4}$ \\ and Shin-ichi Yusa ${ }^{1, *}$ \\ 1 Department of Applied Chemistry, University of Hyogo, 2167 Shosha, Himeji, Hyogo 671-2280, Japan; \\ good.west.56@hotmail.co.jp \\ 2 Department of Materials Engineering, The University of Tokyo, 7-3-1 Hongo, Bunkyo-ku, Tokyo 113-8656, \\ Japan; ishihara@mpc.t.u-tokyo.ac.jp \\ 3 Max Planck Institute for Polymer Research, Ackermannweg 10, 55128 Mainz, Germany; \\ kappl@mpip-mainz.mpg.de \\ 4 Department of Applied Chemistry, Faculty of Engineering, Osaka Institute of Technology, 5-16-1 Omiya, \\ Asahi-ku, Osaka 535-8585, Japan; syuji.fujii@oit.ac.jp (S.F.); yoshinobu.nakamura@oit.ac.jp (Y.N.) \\ * Correspondence: yusa@eng.u-hyogo.ac.jp; Tel.: +81-79-267-4954
}

Academic Editor: Roland G. Winkler

Received: 31 December 2016; Accepted: 30 January 2017; Published: 4 February 2017

\begin{abstract}
Diblock copolymers consisting of a hydrophilic poly(2-(methacryloyloxy)ethyl phosphorylcholine) (PMPC) block and either a cationic or anionic block were prepared from (3-(methacrylamido)propyl)trimethylammonium chloride (MAPTAC) or sodium 2-(acrylamido)-2methylpropanesulfonate (AMPS). Polymers were synthesized via reversible addition-fragmentation chain transfer (RAFT) radical polymerization using a PMPC macro-chain transfer agent. The degree of polymerization for PMPC, cationic PMAPTAC, and anionic PAMPS blocks was 20, 190, and 196, respectively. Combining two solutions of oppositely charged diblock copolymers, PMPC- $b$-PMAPTAC and PMPC- $b$-PAMPS, led to the spontaneous formation of polyion complex vesicles (PICsomes). The PICsomes were characterized using ${ }^{1} \mathrm{H}$ NMR, static abd dynamic light scattering, transmittance electron microscopy (TEM), and atomic force microscopy. Maximum hydrodynamic radius $\left(R_{\mathrm{h}}\right)$ for the PICsome was observed at a neutral charge balance of the cationic and anionic diblock copolymers. The $R_{\mathrm{h}}$ value and aggregation number $\left(N_{\mathrm{agg}}\right)$ of PICsomes in $0.1 \mathrm{M}$ $\mathrm{NaCl}$ was $78.0 \mathrm{~nm}$ and 7770, respectively. A spherical hollow vesicle structure was observed in TEM images. The hydrodynamic size of the PICsomes increased with concentration of the diblock copolymer solutions before mixing. Thus, the size of the PICsomes can be controlled by selecting an appropriate preparation method.
\end{abstract}

Keywords: block copolymers; polyion complex; RAFT polymerization; water-soluble polymers; vesicle

\section{Introduction}

Polymer vesicles prepared by self-association of block copolymers, which are of great interest because of their potential application in fields such as materials science and biochemistry. Usually, polymer vesicles are prepared by self-assembly of amphiphilic block copolymers by the solvent switch method [1,2] or the organic-solvent free method [3]. For the solvent switch method, an amphiphilic diblock copolymer is dissolved in an organic solvent that can be mixed with water, such as dimethylsulfoxide (DMSO), N,N-diethylformamide (DMF), tetrahydrofuran (THF), or 1,4-dioxane, to prepare a homogeneous polymer solution, followed by the gradual addition water to the organic solvent solution. The hydrophilic block chains become solvated to form the vesicle shell, which 
stabilizes the polymer vesicle, whereas the hydrophobic blocks associate to form the vesicle membrane. It is difficult to control vesicle size using this method because the self-assembly process depends heavily on the rate of solvent mixing. Moreover, further purification using dialysis is required to remove the organic solvent. This process is time-consuming and economically unfavorable. Furthermore, many factors, such as the initial polymer concentration, organic solvent characteristics, additives used, and temperature, affect the morphology of the polymer aggregates [4]. Polymer vesicle preparation without the use of an organic solvent usually involves rehydration of the block copolymer in water. The diblock copolymer is dissolved directly in water to form the polymer vesicle, but long and vigorous agitation is usually necessary to fully hydrate the block copolymer. However, this method results in broad size distributions [5,6].

Kataoka and Kishimura [7] reported the elegant formation of polyion complex vesicles (PICsomes) from oppositely charged diblock copolymers of cationic poly(ethylene glycol) (PEG)-block-poly ((5-aminopentyl)- $\alpha, \beta$-aspartamide) (PEG-P(Asp-AP)) and anionic PEG-block-poly $(\alpha, \beta$-aspartic acid) (PEG-PAsp). The degree of polymerization (DP) for PEG, P(Asp-AP), and PAsp is 45, 75, and 75, respectively. Aqueous solutions of PEG-P(Asp-AP) and PEG-PAsp are prepared separately, and are mixed to prepare the PICsomes. In general, PEG is used as a hydrophilic segment for biocompatible materials because PEG suppresses non-specific protein adsorption due to its solvophilicity, large exclusion volume effect, and high mobility. The PICsome composed of PEG-P(Asp-AP) and PEG-PAsp is a potential candidate as a carrier for drug delivery systems (DDS) because the PICsome surface is surrounded by biocompatible PEG shells. However, the preparation of PICsomes involves the time-consuming processes of protection and deprotection during the syntheses of $\mathrm{P}(\mathrm{Asp}-\mathrm{AP})$ and PAsp. Stuart and co-workers [8,9] reported water-soluble polyion complex micelles formed from oppositely charged polymers. Schrage and co-workers [10] reported PICsomes with a corona of segregated polymer chains formed from oppositely charged block ionomers in THF.

Preparation of a pair of oppositely charged doubly hydrophilic diblock copolymers, PEG-block-poly((3-(methacrylamido)propyl)trimethylammonium chloride) (PEG-b-PMAPTAC) and PEG-block-poly(sodium 2-(acrylamido)-2-methylpropanesulfonate) (PEG-b-PAMPS), was reported via reversible addition-fragmentation chain transfer (RAFT) radical polymerization using a PEG-based chain transfer agent (CTA) [11]. A stoichiometrically charged neutral mixture of these oppositely charged diblock copolymers forms water-soluble PIC micelles in water. In addition, preparation of poly(2-(methacryloyloxy)ethyl phosphorylcholine)-block-PMAPTAC (PMPC-b-PMAPTAC) and PMPC- $b$-PAMPS has been reported via RAFT using PMPC-based CTA with DP $=100$ [12]. Diblock copolymers with different, well-controlled PMAPTAC (DP = 27, 48, and 96) and PAMPS (DP = 27, 45 , and 99) block lengths were obtained. The PMPC possesses excellent blood compatibility, that is, PMPC does not induce hemolysis and activation of platelets when it is in contact with blood, due to a polyampholyte containing both positive and negative charges in its phosphorylcholine group [13]. Mixing aqueous solutions of PMPC- $b$-PMAPTAC and PMPC- $b$-PAMPS leads to the spontaneous formation of simple core-shell PIC micelles composed of a PIC core and PMPC shells.

The shapes of self-assemblies formed from amphiphilic block copolymers in water are influenced by the hydrophilic/hydrophobic balance. They change from spherical micelles, thread-like micelles, and vesicles upon an increase in molecular weight of the hydrophobic block $[14,15]$. We would like to confirm PIC aggregates with a small volume fraction of water-soluble part form vesicle structures similar to conventional amphiphilic block copolymers. In the present study, cationic MAPTAC and anionic AMPS were polymerized using short-chain-length PMPC-based CTA with DP $=20$ via RAFT radical polymerization to obtain a pair of oppositely charged diblock copolymers. These diblock copolymers were composed of short-chain-length PMPC blocks and long-chain-length charged blocks (PAMPS or PMAPTAC). The DP value of the charged blocks was about 10 times larger than that of the PMPC block. Polyion complex vesicles (PICsomes) were formed by mixing these two oppositely charged diblock copolymers, which were characterized. The expected PICsome structure is shown in Figure 1. The hydrated PMPC shells were covered on the inside and outside by a PICsome 
membrane composed of PMAPTAC and PAMPS blocks. This PICsome was thought to have the ability to incorporate nonionic water-soluble guest molecules into its hollow core.
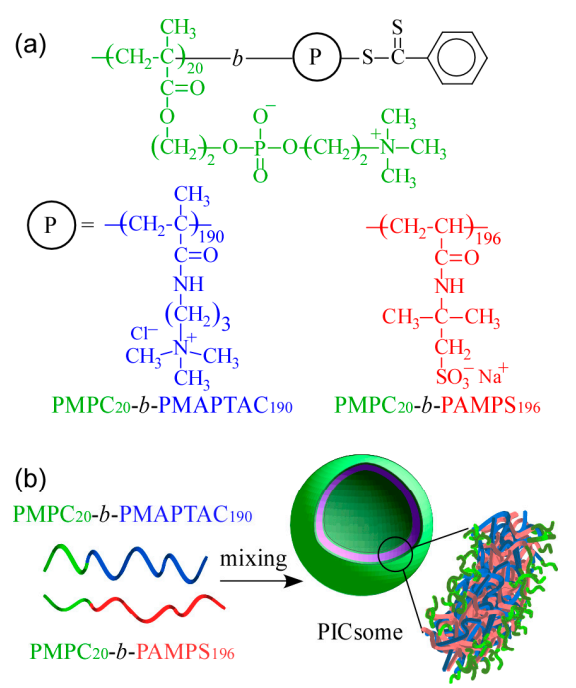

Figure 1. (a) Chemical structures of oppositely charged diblock copolymers, poly(2-(methacryloyloxy) ethyl phosphorylcholine)-block-poly((3-(methacrylamido)propyl) trimethylammonium chloride) (PMPC 20 -b-PMAPTAC $190, \mathrm{P}_{20} \mathrm{M}_{190}$ ) and poly(2-(methacryloyloxy) ethyl phosphorylcholine)-block-poly (sodium 2-(acrylamido)-2-methylpropanesulfonate) ( $\mathrm{PMPC}_{20}-b$-PAMPS ${ }_{196}, \mathrm{P}_{20} \mathrm{~A}_{196}$ ); (b) conceptual illustration of a polyion complex vesicle (PICsome) composed of a stoichiometric charge-neutral mixture of $\mathrm{P}_{20} \mathrm{M}_{190}$ and $\mathrm{P}_{20} \mathrm{~A}_{196}$.

\section{Materials and Methods}

\subsection{Materials}

2-(Methacryloyloxy)ethyl phosphorylcholine (MPC) was synthesized as previously reported and recrystallized from acetonitrile [16]. 4-Cyanopentanoic acid dithiobenzoate (CPD) was synthesized according to the method reported by McCormick and co-workers [17]. Methanol was dried over $4 \AA$ molecular sieves and then distilled. The phosphate buffered saline (PBS) tablet was purchased from Sigma Aldrich (St Louis, MO, USA) and one tablet was dissolved in $200 \mathrm{~mL}$ purified water. (3-(Methacrylamido)propyl)trimethylammonium chloride (MAPTAC, 96\%), 2-(acrylamido)-2-methylpropanesulfonic acid (AMPS, 95\%), and 4,4'-azobis(4-cyanopentanoic acid) (V-501, 98\%) were purchased from Wako Pure Chemical (Osaka, Japan) and Texas red-labeled dextran (Dex, $M_{\mathrm{W}}=70,000$, neutral) from Life Technologies (Tokyo, Japan) and were used as received without further purification. Water was purified using ion exchange. Other reagents were used as received.

\subsection{Preparation of $P M P C$}

The PMPC macro-chain transfer agent (PMPC macro-CTA) was prepared according to a method modified from previously reports [18]. MPC $(6.03 \mathrm{~g}, 20.4 \mathrm{mmol})$ was dissolved in a mixture of methanol and water $(38.8 \mathrm{~mL}, 7 / 5, v / v)$, followed by addition of CPD $(423 \mathrm{mg}, 1.38 \mathrm{mmol})$ and V-501 $(48.0 \mathrm{mg}, 0.171 \mathrm{mmol})$ to the solution. The solution was degassed by purging with argon gas for $0.5 \mathrm{~h}$. Polymerization was performed at $70{ }^{\circ} \mathrm{C}$ for $6 \mathrm{~h}$. The reaction mixture was dialyzed against pure water for two days. PMPC was obtained by freeze-drying $(6.05 \mathrm{~g}, 93.8 \%)$. The number-average molecular weight $\left(M_{\mathrm{n}}(\mathrm{NMR})\right)$, degree of polymerization (DP) estimated from ${ }^{1} \mathrm{H} \mathrm{NMR}$, and molecular weight distribution $\left(M_{\mathrm{W}} / M_{\mathrm{n}}\right)$ estimated from gel-permeation chromatography (GPC) were $6.21 \times 10^{3} \mathrm{~g} / \mathrm{mol}$, 20 , and 1.03 , respectively. 


\subsection{Preparation of $P M P C_{20}-b-P M A P T A C_{190}\left(P_{20} M_{190}\right)$}

PMPC macro-CTA (345 mg, $\left.56.5 \mu \mathrm{mol}, M_{\mathrm{n}}(\mathrm{NMR})=6.21 \times 10^{3} \mathrm{~g} / \mathrm{mol}, M_{\mathrm{w}} / M_{\mathrm{n}}=1.03\right)$, MAPTAC $(2.50 \mathrm{~g}, 11.3 \mathrm{mmol})$, and V-501 (7.90 mg, $28.2 \mu \mathrm{mol})$ were dissolved in water (22.6 mL). The solution was deoxygenated by purging with argon gas for $0.5 \mathrm{~h}$. Polymerization was conducted at $70^{\circ} \mathrm{C}$ for $6 \mathrm{~h}$. The diblock copolymer was purified by dialysis against pure water for two days. The cationic diblock copolymer $\left(\mathrm{P}_{20} \mathrm{M}_{190}\right)$ was recovered using freeze-drying $\left(2.46 \mathrm{~g}, 85.9 \%, M_{\mathrm{n}}(\mathrm{NMR})=4.95 \times 10^{4} \mathrm{~g} / \mathrm{mol}\right.$, $\left.M_{\mathrm{W}} / M_{\mathrm{n}}=1.05\right)$.

\subsection{Preparation of $P M P C_{20}-b-P A M P S_{196}\left(P_{20} A_{196}\right)$}

A predetermined amount of AMPS $(2.00 \mathrm{~g}, 9.67 \mathrm{mmol})$ was neutralized with $1 \mathrm{M} \mathrm{NaOH}$ in $9.65 \mathrm{~mL}$ of water. Then, PMPC macro-CTA (300 mg, $48.3 \mu \mathrm{mol}, M_{\mathrm{n}}(\mathrm{NMR})=6.21 \times 10^{3} \mathrm{~g} / \mathrm{mol}, M_{\mathrm{w}} / M_{\mathrm{n}}=1.03$ ) and V-501 $(10.7 \mathrm{mg}, 38.2 \mu \mathrm{mol})$ was added to the solution, which was deoxygenated by purging with argon gas for $30 \mathrm{~min}$. Polymerization was performed at $70{ }^{\circ} \mathrm{C}$ for $3 \mathrm{~h}$. The diblock copolymer was purified by dialysis against pure water for two days. The anionic diblock copolymer $\left(\mathrm{P}_{20} \mathrm{~A}_{196}\right)$ was obtained by freeze-drying $\left(2.25 \mathrm{~g}, 88.8 \%, M_{\mathrm{n}}(\mathrm{NMR})=4.85 \times 10^{4} \mathrm{~g} / \mathrm{mol}, M_{\mathrm{w}} / M_{\mathrm{n}}=1.07\right)$.

\subsection{Preparation of Polyion Complex Vesicles (PICsomes)}

The $\mathrm{P}_{20} \mathrm{M}_{190}$ and $\mathrm{P}_{20} \mathrm{~A}_{196}$ were dissolved separately in $\mathrm{NaCl}$ aqueous solutions, and the solutions were left standing overnight at room temperature to achieve complete dissolution. $\mathrm{A}_{20} \mathrm{M}_{190}$ solution was added dropwise to a $\mathrm{P}_{20} \mathrm{~A}_{196}$ solution over a period of $5 \mathrm{~min}$ at room temperature with stirring to prepare the PIC vesicles (PICsomes), and the mixture was left standing for at least $1 \mathrm{~h}$ prior to measurement. The mixing ratio of the block copolymers was represented by the mole fraction of positively charged unit $\left(f^{+}=[\mathrm{MAPTAC}] /([\mathrm{AMPS}]+[\mathrm{MAPTAC}])\right)$ and hence complete charge neutralization was achieved at $f^{+}=0.5$.

\subsection{Encapsulation of Texas Red-Labeled Dextran (Dex)}

Dex $\left(0.040 \mathrm{mg}, 5.71 \times 10^{-10} \mathrm{~mol}\right)$ was dissolved in PBS buffer $(4 \mathrm{~mL})$, and $\mathrm{P}_{20} \mathrm{M}_{190}(0.5 \mathrm{~g} / \mathrm{L})$ and $\mathrm{P}_{20} \mathrm{~A}_{196}(0.5 \mathrm{~g} / \mathrm{L})$ were dissolved in PBS buffer solutions containing Dex separately. The solutions were allowed to stand overnight at room temperature. The $\mathrm{P}_{20} \mathrm{M}_{190}$ solution was added to the $\mathrm{P}_{20} \mathrm{~A}_{196}$ solution over a period of $5 \mathrm{~min}$ with stirring. The $f^{+}$value was kept constant at 0.5 . The solution $(4 \mathrm{~mL})$ was dialyzed using a polycarbonate membrane with 100-nm pore size (Harvard Apparatus, Holliston, MA, USA) against fresh PBS buffer $(400 \mathrm{~mL})$ for $18 \mathrm{~h}$, changing the PBS buffer 3 times to remove the free Dex that was not incorporated into the hollow core of the PICsome. After dialysis, fluorescence emission of the PBS buffer in the dialyzer was measured. As a reference, fluorescence of the PBS buffer solution of Dex without PICsomes was also measured using a similar procedure. The weight of the Dex incorporated into the PICsomes was calculated using a calibration curve. The loading efficiency (LE) and loading capacity (LC) of Dex were calculated according to the following equations:

$$
\begin{aligned}
& \text { LE }(\%)=\frac{\text { Weight of encapsulated Dex }}{\text { Weight of total Dex }} \times 100, \\
& \text { LC }(\%)=\frac{\text { Weight of encapsulated Dex }}{\text { Weight of polymer }} \times 100 .
\end{aligned}
$$

\subsection{Measurements}

The GPC measurements for the cationic polymer were obtained using a Jasco (Tokyo, Japan) RI-2031 Plus refractive index detector equipped with a Jasco PU-8020 pump and a Shodex (Tokyo, Japan) OHpak SB-804 HQ column (exclusion limit $\sim 10^{7}$ ) working at $40{ }^{\circ} \mathrm{C}$ under a flow rate of $0.60 \mathrm{~mL} / \mathrm{min}$. A $0.30 \mathrm{M}$ aq. $\mathrm{Na}_{2} \mathrm{SO}_{4}$ solution containing $0.50 \mathrm{M}$ acetic acid was used as the eluent. The values of $M_{\mathrm{n}}(\mathrm{GPC})$ and $M_{\mathrm{w}} / M_{\mathrm{n}}$ were calibrated using standard poly(2-vyniypyridine) samples. 
The GPC measurements for the anionic polymer were obtained using a Tosoh RI-8020 refractive index detector (Tosoh, Tokyo, Japan) equipped with a Shodex 7.0- $\mu \mathrm{m}$ bead size GF-7M HQ column (exclusion limit $\sim 10^{7}$ ) working at $40{ }^{\circ} \mathrm{C}$ under a flow rate of $0.60 \mathrm{~mL} / \mathrm{min}$. A phosphate buffer (50 mM, pH 9.0) containing $10 \mathrm{vol} \%$ acetonitrile was used as the eluent. The values of $M_{n}$ (GPC) and $M_{\mathrm{w}} / M_{\mathrm{n}}$ were determined using standard sodium poly(styrenesulfonate) samples. ${ }^{1} \mathrm{H}$ NMR spectra were obtained with a Bruker (Yokohma, Japan) DRX-500 spectrometer operating at $500.13 \mathrm{MHz}$ with a deuterium lock. Light-scattering measurements were performed using an Otsuka Electronics Photal (Osaka, Japan) DLS-7000HL equipped with a multi- $\tau$, digital time correlator (ALV-5000E). A helium-neon (He-Ne) laser $(10.0 \mathrm{~mW}$ at $632.8 \mathrm{~nm})$ was used as a light source. Sample solutions for light scattering measurements were filtered with a $0.45-\mu \mathrm{m}$ membrane filter. From static light scattering (SLS) measurements, the weight-average molecular weight $\left(M_{\mathrm{w}}\right), z$-average radius of gyration $\left(R_{\mathrm{g}}\right)$, and second virial coefficient $\left(A_{2}\right)$ values were calculated by the relation:

$$
\frac{K C_{\mathrm{p}}}{R_{\theta}}=\frac{1}{M_{\mathrm{w}}}\left(1+\frac{1}{3} R_{g}^{2} q^{2}\right)+2 A_{2} C_{\mathrm{p}}
$$

where $R_{\theta}$ is the difference between the Rayleigh ratio of the solution and that of the solvent, $K=4 \pi^{2} n^{2}\left(\mathrm{~d} n / \mathrm{d} C_{\mathrm{p}}\right)^{2} / N_{\mathrm{A}} \lambda^{4}$ with $\mathrm{d} n / \mathrm{d} C_{\mathrm{p}}$ being the refractive index increment against $C_{\mathrm{p}}, N_{\mathrm{A}}$ being Avogadro's number, and $q$ the magnitude of the scattering vector. The $q$ value was calculated from $q=(4 \pi n / \lambda) \sin (\theta / 2)$, where $n$ is the refractive index of the solvent, $\lambda$ is the light source wavelength $(=632.8 \mathrm{~nm})$, and $\theta$ is the scattering angle. By measuring $R_{\theta}$ for a set of $C_{\mathrm{p}}$ and $\theta$, values of $M_{\mathrm{w}}, R_{\mathrm{g}}$, and $A_{2}$ were estimated from Zimm plots. The known Rayleigh ratio of toluene was used for calibration of the instrument. Values of $\mathrm{d} n / \mathrm{d} C_{\mathrm{p}}$ at $633 \mathrm{~nm}$ were determined using an Otsuka Electronics Photal (Osaka, Japan) DRM-3000 differential refractometer. In our dynamic light scattering (DLS) experiments, inverse Laplace transform (ILT) analysis was performed using the REPES algorithm [19-21] to obtain the relaxation time distribution, $\tau A(\tau)$. The relaxation rate $\left(\Gamma=\tau^{-1}\right)$ is a function of $\theta$ [22]. The diffusion coefficient in the limit of zero angle $(D)$ was calculated from $D=\left(\Gamma / q^{2}\right)_{q \rightarrow 0}$. The hydrodynamic radius $\left(R_{\mathrm{h}}\right)$ was provided by the Stokes-Einstein equation, $R_{\mathrm{h}}=k_{\mathrm{B}} T /(6 \pi \eta D)$, where $k_{\mathrm{B}}$ is Boltzmann constant, $T$ is absolute temperature, and $\eta$ is solvent viscosity. The $\zeta$-potential measurements were obtained using a Malvern (Worcestershire, UK) Zetasizer Nano-ZS ZEN3600 equipped with a He-Ne laser light source $(4 \mathrm{~mW}$ at $632.8 \mathrm{~nm})$. The $\zeta$-potential was calculated from the electrophoretic mobility $(\mu)$ using the Smoluchowski relation, $\zeta=\eta \mu / \varepsilon(\kappa a>>1)$, where $\eta$ is viscosity, $\varepsilon$ is the dielectric constant of the medium, and $\mathrm{k}$ and $a$ are the Debye-Hückel parameter and particle radius, respectively [23]. Transmission electron microscopy (TEM) observations were performed using a Jeol JEM-2100 instrument at an accelerating voltage of $200 \mathrm{kV}$. Samples for TEM were prepared by placing one drop of the aqueous solution on a copper grid coated with thin films of Formvar. Excess water was blotted using filter paper. The samples were stained by sodium phosphotungstate and dried under vacuum for one day. Atomic force microscope (AFM) observations were performed with a JPK Nano Wizard 3 (JPK Instruments, Berlin, Germany) microscope. The sample of PICsome was applied onto a freshly cleaved mica surface. Excess water was blotted using filter paper and the sample dried for $10 \mathrm{~min}$ at $25^{\circ} \mathrm{C}$. Measurements were obtained in tapping mode using the Olympus (Tokyo, Japan) OMCLAC $160 \mathrm{TN}-\mathrm{W} 2$ silicon AFM probes (nominal spring constant, $k=42 \mathrm{~N} / \mathrm{m}$, resonance frequency ca. $300 \mathrm{kHz}$, tip radius $<10 \mathrm{~nm}$ ). Height and size information were extracted using JPK data processing software (Version 5.1.8, JPK Instruments, Berlin, Germany). Fluorescence emission spectra were recorded on a Hitachi (Tokyo, Japan) F-2500 fluorescence spectrophotometer. Fluorescence spectra of Dex were measured with excitation at $550 \mathrm{~nm}$. Excitation and emission slit widths were maintained at $10 \mathrm{~nm}$.

\section{Results and Discussion}

To obtain oppositely charged diblock copolymers $\left(\mathrm{P}_{20} \mathrm{M}_{190}\right.$ and $\left.\mathrm{P}_{20} \mathrm{~A}_{196}\right)$, block copolymerization was conducted using PMPC macro-CTA with DP $=20$ via RAFT radical polymerization. 
The conversions of MAPTAC and AMPS were estimated from ${ }^{1} \mathrm{H}$ NMR measurements after polymerization reached $93.0 \%$ and $95.0 \%$, respectively. The molecular characteristics of PMPC, $\mathrm{P}_{20} \mathrm{M}_{190}$, and $\mathrm{P}_{20} \mathrm{~A}_{196}$ are summarized in Table 1 . The theoretical number-average molecular weight $\left(M_{\mathrm{n}}(\right.$ theo) was calculated using:

$$
M_{\mathrm{n}}(\text { theo })=\frac{[\mathrm{M}]_{0}}{[\mathrm{CTA}]_{0}} x_{\mathrm{m}} M_{\mathrm{m}}+M_{\mathrm{CTA}}
$$

where $[\mathrm{M}]_{0}$ is initial monomer concentration, $[\mathrm{CTA}]_{0}$ is initial CTA concentration, $x_{\mathrm{m}}$ is the conversion of monomer, $M_{\mathrm{m}}$ is the molecular weight of the monomer, and $M_{\mathrm{CTA}}$ is the molecular weight of the CTA. The $M_{n}(\mathrm{NMR})$ and $M_{\mathrm{n}}(\mathrm{GPC})$ for PMPC were close to the theoretical $M_{\mathrm{n}}$ (theo) value, and the molecular weight distribution $\left(M_{\mathrm{w}} / M_{\mathrm{n}}\right)$ was narrow $(=1.03)$, indicating the controlled mechanism of the polymerization. Values obtained from ${ }^{1} \mathrm{H}$ NMR to determine the true molecular weight of $\mathrm{P}_{20} \mathrm{M}_{190}$ and $\mathrm{P}_{20} \mathrm{~A}_{196}$ yielded $M_{\mathrm{n}}(\mathrm{NMR})=4.95 \times 10^{4}$ and $4.85 \times 10^{4} \mathrm{~g} / \mathrm{mol}$, which was in fair agreement with $M_{\mathrm{n}}$ (theo) $=4.82 \times 10^{4}$ and $4.68 \times 10^{4} \mathrm{~g} / \mathrm{mol}$, respectively. The $M_{\mathrm{n}}(\mathrm{GPC})$ value for $\mathrm{P}_{20} \mathrm{M}_{190}$ and $\mathrm{P}_{20} \mathrm{~A}_{196}$ deviated markedly from $M_{\mathrm{n}}$ (theo). Note that the $M_{\mathrm{n}}(\mathrm{GPC})$ values estimated by GPC were only apparent values because of the inherent error involved in the use of molecular weight standards [poly(2-vinylpyridine) and sodium poly(styrenesulfonate)] for calibrating the GPC data.

Table 1. Number-average molecular weight $\left(M_{n}\right)$, number-average degree of polymerization (DP), and molecular weight distribution $\left(M_{\mathrm{w}} / M_{\mathrm{n}}\right)$ for the samples.

\begin{tabular}{cccccc}
\hline Sample & $\begin{array}{c}\boldsymbol{M}_{\mathbf{n}} \mathbf{( t h e o ~}^{a} \times \mathbf{1 0}^{\mathbf{4}} \\
(\mathbf{g} / \mathbf{m o l})\end{array}$ & $\begin{array}{c}\boldsymbol{M}_{\mathbf{n}}(\mathbf{N M R}) \times \mathbf{1 0}^{\mathbf{4}} \\
(\mathbf{g} / \mathbf{m o l})\end{array}$ & DP(NMR) & $\begin{array}{c}\boldsymbol{M}_{\mathbf{n}}(\mathrm{GPC}) \times \mathbf{1 0 ^ { 4 }} \\
(\mathbf{g} / \mathbf{m o l})\end{array}$ & $\boldsymbol{M}_{\mathbf{w}} / \boldsymbol{M}_{\mathbf{n}}$ \\
\hline $\mathrm{PMPC}$ & 0.613 & 0.621 & 20 & $0.735^{b}$ & $1.03^{b}$ \\
$\mathrm{P}_{20} \mathrm{M}_{190}$ & 4.82 & 4.95 & 190 & $2.40^{c}$ & $1.05^{c}$ \\
$\mathrm{P}_{20} \mathrm{~A}_{196}$ & 4.68 & 4.85 & 196 & $2.77^{b}$ & $1.07^{b}$ \\
\hline
\end{tabular}

${ }^{a}$ Calculated using Equation (4). ${ }^{b}$ Estimated from gel-permeation chromatography (GPC) using phosphate buffer (50 mM, pH 9.0) containing $10 \mathrm{vol} \%$ acetonitrile as eluent. ${ }^{c}$ Estimated from GPC using aq. $0.30 \mathrm{M} \mathrm{Na}_{2} \mathrm{SO}_{4}$ containing $0.50 \mathrm{M}$ acetic acid as eluent.

Figure $2 \mathrm{a}, \mathrm{b}$ show the ${ }^{1} \mathrm{H}$ NMR spectra for $\mathrm{P}_{20} \mathrm{M}_{190}$ and $\mathrm{P}_{20} \mathrm{~A}_{196}$, respectively. The resonance bands observed in the $0.8-1.2 \mathrm{ppm}$ region and at $1.8 \mathrm{ppm}$ were attributed to the $\alpha$-methyl protons and main chain methylene protons, respectively (Figure 2a). The DP and $M_{n}(\mathrm{NMR})$ values of the PMAPTAC block in $\mathrm{P}_{20} \mathrm{M}_{190}$ were determined from the integral intensity ratio of the resonance bands due to pendant methyl protons in the PMAPTAC block at 3.1 ppm and PMPC pendant methylene protons at $3.7 \mathrm{ppm}$. The resonance bands observed at 1.2-2.2 ppm for $\mathrm{P}_{20} \mathrm{~A}_{196}$ were attributed to the sum of the main chain and pendent methyl groups in the PAMPS block (Figure 2b). Values for DP and $M_{n}(\mathrm{NMR})$ of the PAMPS block in $\mathrm{P}_{20} \mathrm{~A}_{196}$ were calculated from the integral intensity ratio of the pendent methylene protons in the PAMPS block at $3.3 \mathrm{ppm}$ and PMPC pendant methylene protons at $3.7 \mathrm{ppm}$. Figure $2 \mathrm{c}$ shows the ${ }^{1} \mathrm{H}$ NMR spectrum for the polyion complex vesicle (PICsome) composed of $\mathrm{P}_{20} \mathrm{M}_{190}$ and $\mathrm{P}_{20} \mathrm{~A}_{196}$ with $f^{+}=0.5$ in $\mathrm{D}_{2} \mathrm{O}$ containing $0.1 \mathrm{M} \mathrm{NaCl}$. The intensity of resonance peaks associated with the PMAPTAC and PAMPS blocks was weak compared with those associated with the PMPC block. These observations suggest that the motion of the PMAPTAC and PAMPS blocks was highly restricted due to formation of the PIC core. The mobility of PMPC chains may be higher than that of the PMAPTAC and PAMPS chains because the PMPC chains form shells surrounding the PIC.

Aggregates formed by electrostatic interactions sometimes depend on the mixing pathway [24-26]. We studied PICsome size dependence on the mixing pathway. A standard method is that a $\mathrm{P}_{20} \mathrm{M}_{190}$ solution was added dropwise to a $\mathrm{P}_{20} \mathrm{~A}_{196}$ solution over a period of $5 \mathrm{~min}$ at room temperature with stirring. The $\mathrm{P}_{20} \mathrm{~A}_{196}$ solution was added to the $\mathrm{P}_{20} \mathrm{M}_{190}$ solution, and the $\mathrm{P}_{20} \mathrm{M}_{190}$ solution was added to the $\mathrm{P}_{20} \mathrm{~A}_{196}$ solution immediately. These two additional methods had no effect on the size of PICsome with $f^{+}=0.5$. 


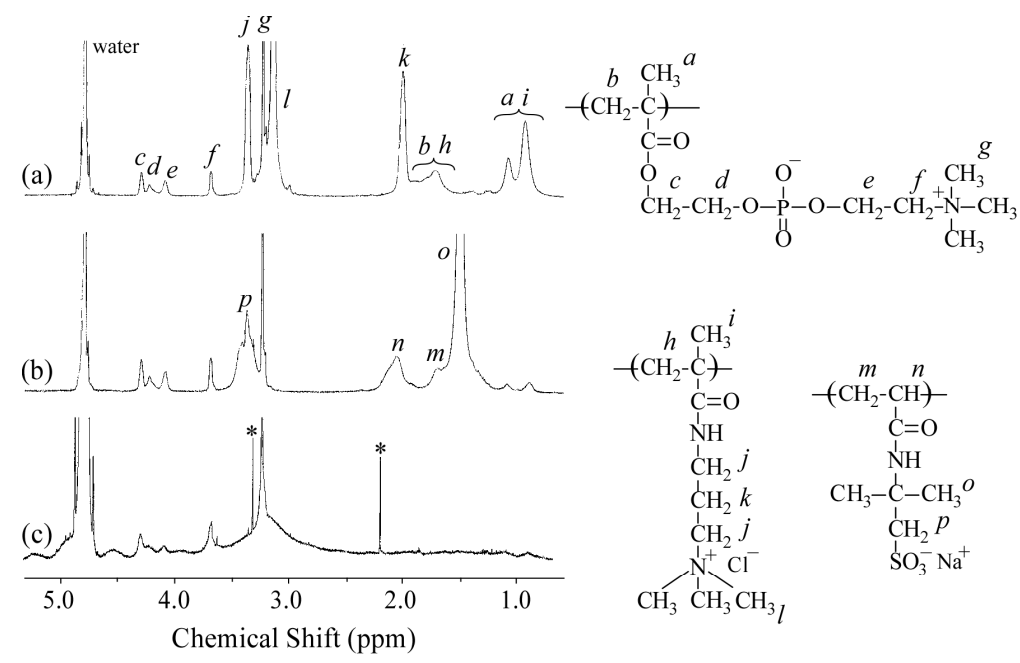

Figure 2. ${ }^{1} \mathrm{H}$ NMR spectra for (a) $\mathrm{P}_{20} \mathrm{M}_{190}$; (b) $\mathrm{P}_{20} \mathrm{~A}_{196}$; and (c) PICsome composed of $\mathrm{P}_{20} \mathrm{M}_{190}$ and $\mathrm{P}_{20} \mathrm{~A}_{196}$ with $f^{+}=0.5$ in a $\mathrm{D}_{2} \mathrm{O}$ solution containing $0.1 \mathrm{M} \mathrm{NaCl}$. Resonance peak assignments are indicated.

Figure 3a shows $R_{\mathrm{h}}$ distributions for $\mathrm{P}_{20} \mathrm{M}_{190}, \mathrm{P}_{20} \mathrm{~A}_{196}$, and the PICsome with $f^{+}=0.5$ in $0.1 \mathrm{M}$ $\mathrm{NaCl}$ at $C_{\mathrm{p}}=0.5 \mathrm{~g} / \mathrm{L}$ and a scattering angle $(\theta)=90^{\circ}$. Unimodal $R_{\mathrm{h}}$ distributions were observed. The $R_{\mathrm{h}}$ values for $\mathrm{P}_{20} \mathrm{M}_{190}, \mathrm{P}_{20} \mathrm{~A}_{196}$, and PICsome were $4.3,4.4$, and $78.0 \mathrm{~nm}$, respectively. The $R_{\mathrm{h}}$ values from 4.3 to $4.4 \mathrm{~nm}$ are reasonable for unimers of these block copolymers. If the polymer main chain forms completely planar zigzag structure, the distance between one carbon to the next carbon is about $0.25 \mathrm{~nm}$ [27]. Hence, we can calculate the end-to-end distance of fully expanded polymer chains. The end-to-end distance of fully extended $\mathrm{P}_{20} \mathrm{M}_{190}$ and $\mathrm{P}_{20} \mathrm{~A}_{196}$ chains were calculated as 52.5 and $54.0 \mathrm{~nm}$, respectively. The $R_{\mathrm{h}}$ of $78.0 \mathrm{~nm}$ found for the PICsome was larger than those expected from the fully extended length of the $\mathrm{P}_{20} \mathrm{M}_{190}$ and $\mathrm{P}_{20} \mathrm{~A}_{196}$ chains. These observations indicate that the shape of the PICsome is not a simple core-shell spherical micelle. Large compound aggregates or vesicles should be formed by mixing $\mathrm{P}_{20} \mathrm{M}_{190}$ and $\mathrm{P}_{20} \mathrm{~A}_{196}$. Relaxation rates $(\Gamma)$ measured at different $\theta$ plotted against the square of the scattering vector $\left(q^{2}\right)$ are shown in Figure $3 \mathrm{~b}$. A line passing through the origin suggests that all of the relaxation modes were virtually diffusive [28].
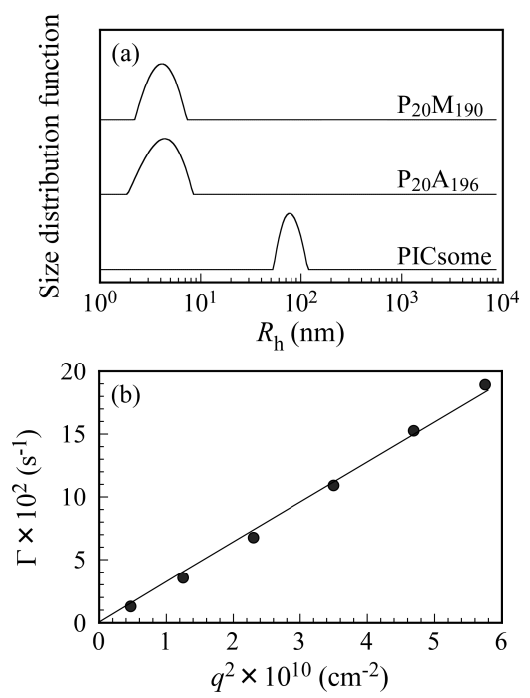

Figure 3. (a) Hydrodynamic radius $\left(R_{\mathrm{h}}\right)$ distributions for $\mathrm{P}_{20} \mathrm{M}_{190}, \mathrm{P}_{20} \mathrm{~A}_{196}$, and PICsome with $f^{+}=0.5$ in aq. $0.1 \mathrm{M} \mathrm{NaCl}$ at $C_{\mathrm{p}}=0.5 \mathrm{~g} / \mathrm{L}$ and at scattering angle $(\theta)=90^{\circ} ;(\mathbf{b})$ relation between relaxation rate $(\Gamma)$ and square of the magnitude of the scattering vector $\left(q^{2}\right)$ for PICsome with $f^{+}=0.5$ at $C_{\mathrm{p}}=0.5 \mathrm{~g} / \mathrm{L}$. 
To confirm the stability of the PICsome size, $R_{\mathrm{h}}$ values were measured at various standing times. The $R_{\mathrm{h}}$ values were nearly constant and independent of time until $150 \mathrm{~h}$, suggesting that the structure of the PICsome does not change with time (data not shown). Scattering intensities of the PICsomes were also independent of time.

To further characterize the PICsomes, SLS measurements were performed for $\theta$ from 30 to $130^{\circ}$ with a $20^{\circ}$ increment. The refractive index increment $\left(\mathrm{d} n / \mathrm{d} C_{\mathrm{p}}\right)$ for $\mathrm{P}_{20} \mathrm{M}_{190}, \mathrm{P}_{20} \mathrm{~A}_{196}$, and PICsome in $0.1 \mathrm{M} \mathrm{NaCl}$ were determined individually. Values for $M_{\mathrm{w}}$ (SLS), $R_{\mathrm{g}}$, and $A_{2}$ were estimated from Zimm plots. Aggregation number $\left(N_{\text {agg }}\right)$ for PICsomes (i.e., number of PMPC shell chains per one PICsome) was calculated by dividing $M_{\mathrm{w}}$ (SLS) with that of unimers. The structure of the PICsome was also characterized by combining DLS and SLS to determine the $R_{\mathrm{g}} / R_{\mathrm{h}}$ ratio. The density $(d)$ of $\mathrm{P}_{20} \mathrm{M}_{190}, \mathrm{P}_{20} \mathrm{~A}_{196}$, and PICsome can be calculated by:

$$
d=\frac{M_{\mathrm{W}}(\mathrm{SLS})}{N_{\mathrm{A}} \times V}
$$

where $V$ is a polymer or PICsome volume calculated from $4 / 3 \pi R_{\mathrm{h}}{ }^{3}$. A summary of the properties of $\mathrm{P}_{20} \mathrm{M}_{190}, \mathrm{P}_{20} \mathrm{~A}_{196}$, and the PICsome, including $M_{\mathrm{w}}(\mathrm{SLS}), N_{\mathrm{agg}}, R_{\mathrm{g}}, R_{\mathrm{h}}, R_{\mathrm{g}} / R_{\mathrm{h}}, A_{2}, \mathrm{~d} n / \mathrm{d} C_{\mathrm{p}}$, and $d$, is provided in Table 2. Values for $M_{\mathrm{w}}$ (SLS) for $\mathrm{P}_{20} \mathrm{M}_{190}$ and $\mathrm{P}_{20} \mathrm{~A}_{196}$ were close to those for the corresponding $M_{\mathrm{n}}$ (theo) and $M_{\mathrm{n}}$ (NMR) values shown in Table 1 . The $M_{\mathrm{w}}(\mathrm{SLS})$ value for the PICsome was $4.50 \times 10^{8} \mathrm{~g} / \mathrm{mol}$, estimated from SLS. The value of $N_{\text {agg }}$ for the PICsome was estimated to be 7770 . The $R_{\mathrm{g}} / R_{\mathrm{h}}$ ratio is a structure-sensitive parameter that provides information about the density distribution of the particles and thereby about particle morphology [29,30]. The $R_{\mathrm{g}} / R_{\mathrm{h}}$ ratio equals 0.775 for a homogeneous hard sphere, 1.0 for a thin hard spherical shell (e.g., vesicle), and increases significantly for a less dense structure and for a polydisperse solution because large molecules of a broad distribution will contribute more to $R_{\mathrm{g}}$ than to $R_{\mathrm{h}}$, provided that internal modes of motion are absent [31]. The large $R_{\mathrm{g}} / R_{\mathrm{h}}$ ratios $(>4)$ for $\mathrm{P}_{20} \mathrm{M}_{190}$ and $\mathrm{P}_{20} \mathrm{~A}_{196}$ suggest that the polymer chains were expanded due to electrostatic repulsions in the pendant ions. The $R_{\mathrm{g}} / R_{\mathrm{h}}$ ratio for a polymeric vesicle may be less than or greater than 1.0, depending on the thickness and density of the wall [32]. The $R_{\mathrm{g}} / R_{\mathrm{h}}$ ratio of the PICsome was 1.12, which is close to unity, indicates that the PICsome was a vesicle [33]. The $A_{2}$ value for the PICsome was less than those for $\mathrm{P}_{20} \mathrm{M}_{190}$ and $\mathrm{P}_{20} \mathrm{~A}_{196}$, suggesting that solubility of the PICsome in $0.1 \mathrm{M} \mathrm{NaCl}$ was less than those of the unimers. The $d$ values for $\mathrm{P}_{20} \mathrm{M}_{190}, \mathrm{P}_{20} \mathrm{~A}_{196}$, and PICsome were calculated to be $0.286,0.273$, and $0.376 \mathrm{~g} / \mathrm{cm}^{3}$, respectively. The $d$ value for the PICsome was slightly larger than those for $P_{20} M_{190}$ and $P_{20} A_{196}$, suggesting that the polymer chains in the PICsome were more densely packed than those of the unimers. The polymer chains of $\mathrm{P}_{20} \mathrm{M}_{190}$ and $\mathrm{P}_{20} \mathrm{~A}_{196}$ expanded due to electrostatic repulsion in the pendant ionic groups in $0.1 \mathrm{M} \mathrm{NaCl}$. Therefore, $\mathrm{P}_{20} \mathrm{M}_{190}$ and $\mathrm{P}_{20} \mathrm{~A}_{196}$ have large $R_{\mathrm{g}} / R_{\mathrm{h}}$ ratios. In contrast, the polymer chains in the PICsome were compact and dense in their vesicular membranes.

Table 2. Dynamic and static light scattering data for $\mathrm{P}_{20} \mathrm{M}_{190}, \mathrm{P}_{20} \mathrm{~A}_{196}$, and polyion complex vesicles (PICsomes).

\begin{tabular}{|c|c|c|c|c|c|c|c|c|}
\hline Sample & $\begin{array}{c}M_{\mathrm{w}}(\mathrm{SLS})^{a} \times 10^{4} \\
(\mathrm{~g} / \mathrm{mol})\end{array}$ & $N_{\text {agg }} b$ & $\begin{array}{l}R_{\mathrm{g}}^{c} \\
(\mathrm{~nm})\end{array}$ & $\begin{array}{l}R_{\mathrm{h}}^{d} \\
(\mathrm{~nm})\end{array}$ & $R_{\mathrm{g}} / R_{\mathrm{h}}$ & $\begin{array}{c}A_{2}^{e}\left(\mathrm{~cm}^{3} \mathrm{~mol} / \mathrm{g}^{2}\right) \\
\times 10^{-4}\end{array}$ & $\begin{array}{c}\mathrm{d} n / \mathrm{d} C_{\mathrm{p}} f \\
(\mathrm{~mL} / \mathrm{g})\end{array}$ & $\begin{array}{c}d^{g} \\
\left(\mathrm{~g} / \mathrm{cm}^{3}\right)\end{array}$ \\
\hline $\mathrm{P}_{20} \mathrm{M}_{190}$ & 5.73 & 1 & 22.2 & 4.3 & 5.14 & 8.13 & 0.166 & 0.286 \\
\hline PICsome $^{h}$ & 45,000 & 7770 & 87.0 & 78.0 & 1.12 & 2.34 & 0.161 & 0.376 \\
\hline
\end{tabular}

${ }^{a}$ Apparent weight-average molecular weight estimated from static light scattering (SLS). ${ }^{b}$ Aggregation number of PICsomes calculated by dividing $M_{\mathrm{W}}$ (SLS) with that of unimers. ${ }^{c}$ Radius of gyration estimated from SLS. ${ }^{d}$ Hydrodynamic radius estimated from dynamic light scattering (DLS). ${ }^{e}$ Second virial coefficient estimated from SLS. ${ }^{f}$ Refractive index increment. ${ }^{g}$ Density of polymers and PICsomes calculated from Equation (5). ${ }^{h}$ PICsome composed of $\mathrm{P}_{20} \mathrm{M}_{190}$ and $\mathrm{P}_{20} \mathrm{~A}_{196}$ with $f^{+}=0.5$. 
The structure of the PICsome was confirmed by TEM observations, which showed incomplete spherical hollow vesicle structures (Figure 4). The vesicle structures may shrink during the drying process done prior to TEM observation. The PICsome diameter determined from the TEM images was $171 \mathrm{~nm}$, which is close to the value obtained from the light scattering data. The AFM height image of the PICsome confirmed that the PICsome formed spherical structures that were slightly flattened due to the adsorption and drying process (Figure 5). The height of the PICsome observed in the AFM image was ca. $100 \mathrm{~nm}$.

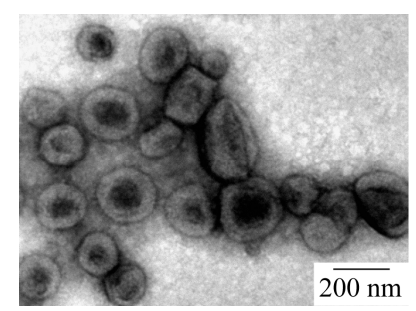

Figure 4. Transmission electron microscopy (TEM) image of the PICsome composed of $\mathrm{P}_{20} \mathrm{M}_{190}$ and $\mathrm{P}_{20} \mathrm{~A}_{196}$ with $f^{+}=0.5$.
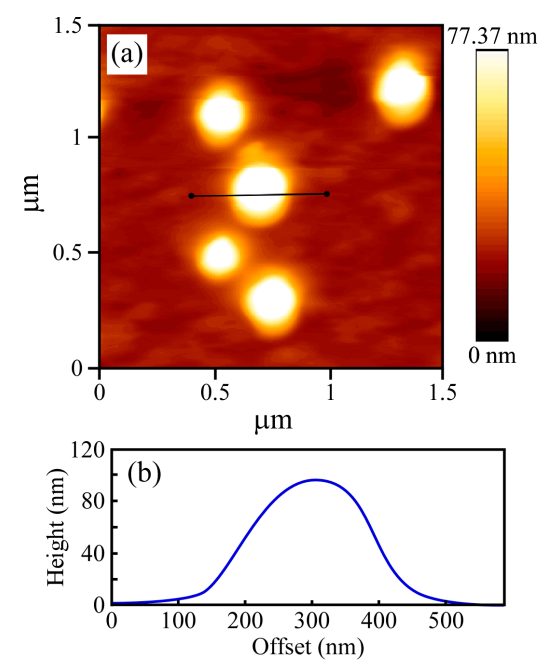

Figure 5. (a) Atomic force microscope (AFM) height image and (b) corresponding height cross-section for the PICsome with $f^{+}=0.5$.

Figure 6a shows the $R_{\mathrm{h}}$ and light scattering intensity values for PICsomes in $0.1 \mathrm{M} \mathrm{NaCl}$ as a function of $f^{+}$. Total polymer concentration was kept constant at $0.5 \mathrm{~g} / \mathrm{L}$. An increase in $R_{\mathrm{h}}$ indicates an increase in the size of the PICsome. The maximum $R_{\mathrm{h}}$ value was observed at $f^{+}=0.5$. In general, scattering intensity depends on molecular weight of the particles. Therefore, an increase in scattering intensity indicates an increase in $N_{\text {agg }}$ for the PICsome, which suggests that stoichiometric charge neutralization in the mixture of the two oppositely charged $\mathrm{P}_{20} \mathrm{M}_{190}$ and $\mathrm{P}_{20} \mathrm{~A}_{196}$ leads to formation of PICsomes with maximum size and aggregation number. Plots of $R_{\mathrm{h}}$ (and scattering intensity) vs. $f^{+}$were asymmetric (i.e., the $R_{\mathrm{h}}$ and scattering intensities for PIC aggregates with $f^{+}=0.6$ and 0.8 were larger than those with $f^{+}=0.4$ ) [34]. To confirm the structure of PIC aggregates with $f^{+}=0.4,0.6$, and 0.8, TEM images were obtained (Figure 7). Results showed that PIC aggregates with $f^{+}=0.4$ were micelle-like spherical particles without a hollow core. In contrast, PIC aggregates with $f^{+}=0.6$ and 0.8 clearly possessed hollow core vesicle structures. The PIC aggregates composed of $\mathrm{P}_{20} \mathrm{M}_{190}$ and $\mathrm{P}_{20} \mathrm{~A}_{196}$ with excess PMAPTAC blocks tended to form vesicles, presumably because the pendant quaternary amino groups surrounded by three methyl groups in the PMAPTAC blocks were more hydrophobic compared to the pendant sulfonate groups in the PAMPS blocks. When $f^{+}$is larger 
than 0.5, excess PMAPTAC blocks existed in the aggregate, dehydration of PIC aggregates was promoted, and solubility was less than that at $f^{+}<0.5$. For aggregates formed from conventional amphiphilic diblock copolymers in water, the greater the hydrophobicity of the aggregate, the more likely diblock copolymers are to form vesicles rather than spherical core-shell micelles [35]. Therefore, PIC aggregates with $f^{+} \geq 0.5$ tend to form vesicles.
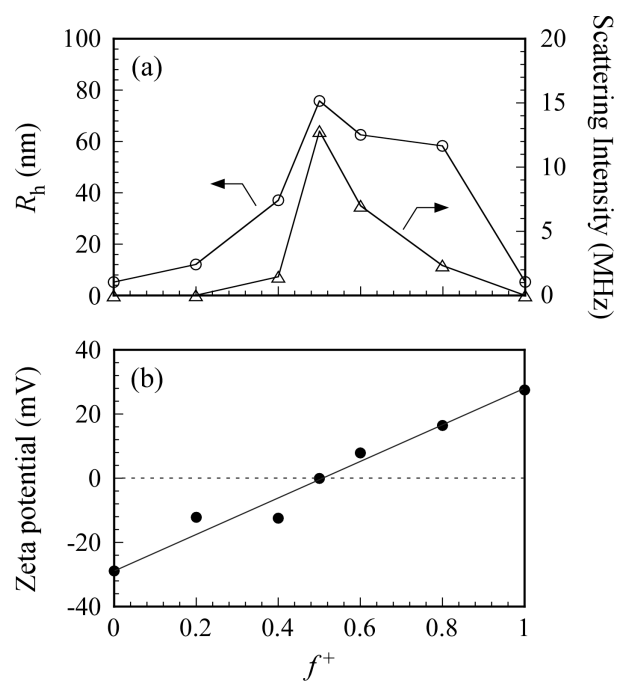

Figure 6. (a) Hydrodynamic radius $\left(R_{\mathrm{h}}, \bigcirc\right)$ and photon counting rate which indicates light scattering intensity $(\triangle)$ for the PICsome composed of $\mathrm{P}_{20} \mathrm{M}_{190}$ and $\mathrm{P}_{20} \mathrm{~A}_{196}$ as a function of $f^{+}$(= [MAPTAC]/ $\left([\mathrm{MAPTAC}]+[\right.$ AMPS]) $)$ in $0.1 \mathrm{M} \mathrm{NaCl} ;(\mathbf{b}) \zeta$-potential for PICsome as a function of $f^{+}$in $0.1 \mathrm{M} \mathrm{NaCl}$. Total polymer concentration was fixed at $0.5 \mathrm{~g} / \mathrm{L}$.
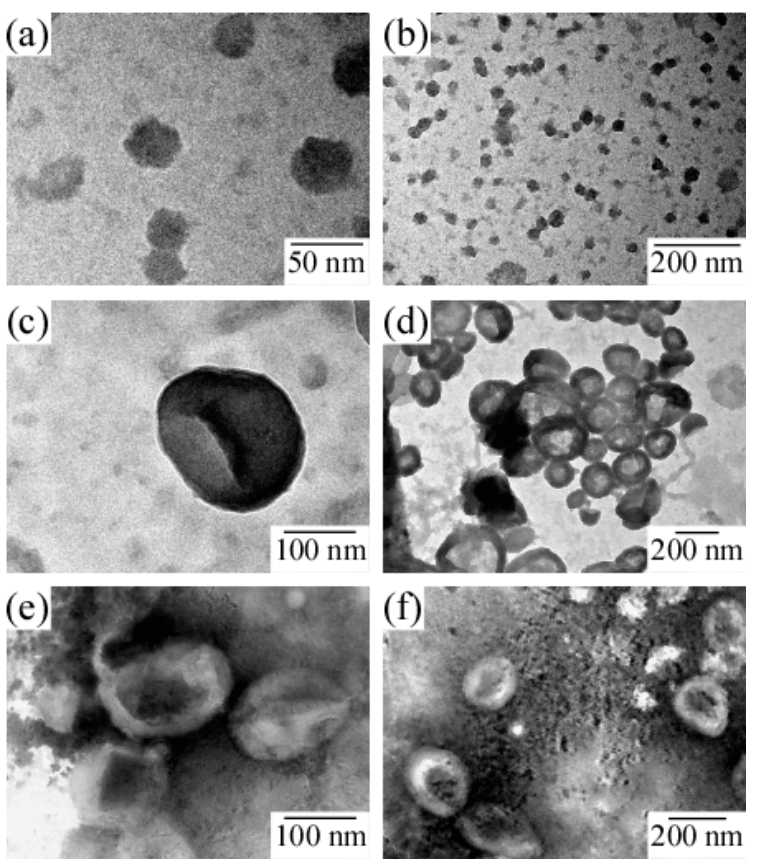

Figure 7. TEM images for PIC aggregates with $f^{+}$values of $(\mathbf{a}, \mathbf{b}) 0.4,(\mathbf{c}, \mathbf{d}) 0.6$, and $(\mathbf{e}, \mathbf{f}) 0.8$.

To confirm PICsome neutralization at $f^{+}=0.5$, the $\zeta$-potential was measured as a function of $f^{+}$ (Figure 6b). At $f^{+}=0$, the aqueous solution of $\mathrm{P}_{20} \mathrm{~A}_{196}$ has a negative $\zeta$-potential value of $-29 \mathrm{mV}$ because the PAMPS block has pendant anionic sulfonate groups. At $f^{+}=1$, the aqueous solution of $\mathrm{P}_{20} \mathrm{M}_{190}$ has a positive $\zeta$-potential value of $+27 \mathrm{mV}$ because the PMAPTAC block has pendant 
cationic quaternary amino groups. The $\zeta$-potential was zero at $f^{+}=0.5$ because the charges of the PAMPS and PMAPTAC blocks were neutralized. The PICsome was composed of a PIC core and PMPC shells. The pendant phosphorylcholine groups in the PMPC shells contain anionic phosphate and cationic quaternary amine. However, the $\zeta$-potential of PMPC homopolymer was zero (data not shown) because of neutralization of the anion and cation pair within a single polymer chain. Therefore, the $\zeta$-potential of PICsome was zero at $f^{+}=0.5$.

To confirm that PICsomes with $f^{+}=0.5$ are at equilibrium or in a kinetically frozen state, excess $\mathrm{P}_{20} \mathrm{~A}_{196}$ was added to the aqueous PICsome solution with $f^{+}=0.5$ to change the $f^{+}$value. A kinetically frozen state means that the polymer chains cannot break free from the aggregate. The size of a PICsome with $f^{+}=0.5$ in the kinetically frozen state should not be affected by the addition of excess $\mathrm{P}_{20} \mathrm{~A}_{196}$. The size of a PICsome in the equilibrium state may decrease upon addition of excess $\mathrm{P}_{20} \mathrm{~A}_{196}$. Figure 8 shows $R_{\mathrm{h}}$ distributions for PICsomes with $f^{+}=0.5$ and PIC aggregates with $f^{+}=0.4$ and 0.2 formed by the addition of $\mathrm{P}_{20} \mathrm{~A}_{196}$ to the PICsome with $f^{+}=0.5$. The $R_{\mathrm{h}}$ value of the PICsome with $f^{+}=0.5$ was $78.0 \mathrm{~nm}$ at $C_{\mathrm{p}}=0.5 \mathrm{~g} / \mathrm{L}$. When a $\mathrm{P}_{20} \mathrm{~A}_{196}$ solution at $C_{\mathrm{p}}=0.5 \mathrm{~g} / \mathrm{L}$ was added to the PICsome solution, which changed the $f^{+}$to 0.4 and 0.2 , the $R_{\mathrm{h}}$ values of the PIC aggregates decreased to 49 and $7.9 \mathrm{~nm}$, respectively. This observation suggested that PICsomes formed by mixing oppositely charged diblock copolymers existed in an equilibrium state in water. Thus, small pairs of the oppositely charged diblock copolymers may dissociate from and associate with the PICsome [36]. $\mathrm{NaCl}$ concentrations in the aqueous solution are very important for stability of PICsomes because they were formed by electrostatic interactions. We measured the $R_{\mathrm{h}}$ values of PICsomes in various $\mathrm{NaCl}$ concentrations. When $\mathrm{NaCl}$ concentration was $0.5 \mathrm{M}$, the $R_{\mathrm{h}}$ value was $77.8 \mathrm{~nm}$, which is close to the value $\left(R_{\mathrm{h}}=78.0 \mathrm{~nm}\right)$ in $0.1 \mathrm{M} \mathrm{NaCl}$ aqueous solutions. Therefore, at least below $0.5 \mathrm{M}$ of $\mathrm{NaCl}$ concentration, PICsomes were stable.

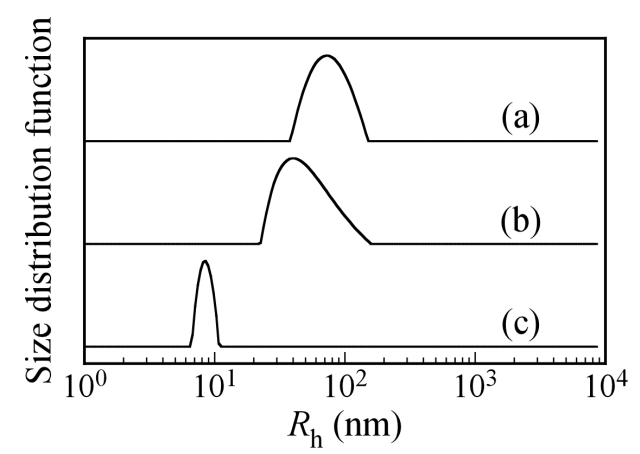

Figure 8. Hydrodynamic radius $\left(R_{\mathrm{h}}\right)$ distributions for (a) PICsomes at $f^{+}=0.5$, and PIC aggregates (b) at $f^{+}=0.4$ and (c) $f^{+}=0.2$ formed by addition of $\mathrm{P}_{20} \mathrm{~A}_{196}$ solution to PICsomes with $f^{+}=0.5$ in $0.1 \mathrm{M}$ aqueous $\mathrm{NaCl}$ solutions at $C_{\mathrm{p}}=0.5 \mathrm{~g} / \mathrm{L}$.

The relation between PICsome size and $C_{\mathrm{p}}$ in $0.1 \mathrm{M} \mathrm{NaCl}$ is shown in Figure 9. The sample solutions were prepared by two different methods. The first method involved preparing separate aqueous $\mathrm{P}_{20} \mathrm{M}_{190}$ and $\mathrm{P}_{20} \mathrm{~A}_{196}$ solutions with a target $C_{\mathrm{p}}$ from 0.001 to $1 \mathrm{~g} / \mathrm{L}$ before mixing a pair of two oppositely charged diblock copolymers. Then, the two aqueous $\mathrm{P}_{20} \mathrm{M}_{190}$ and $\mathrm{P}_{20} \mathrm{~A}_{196}$ solutions with the same $C_{\mathrm{p}}$ were mixed to form a PICsome solution (Figure 9a). The second method involved mixing pairs of oppositely charged diblock copolymer solutions at $C_{\mathrm{p}}=1,0.5$, and $0.01 \mathrm{~g} / \mathrm{L}$ to form PICsomes. Subsequently, the aqueous PICsome solutions were diluted with $0.1 \mathrm{M} \mathrm{NaCl}$ to adjust $C_{\mathrm{p}}$ to the target value (Figure $9 \mathrm{~b}$ ). These PICsome solutions prepared via these two $C_{\mathrm{p}}$ adjustment methods were measured using DLS to determine $R_{\mathrm{h}}$. The $R_{\mathrm{h}}$ values for PICsomes depended on the value of $C_{\mathrm{p}}$ of the $\mathrm{P}_{20} \mathrm{M}_{190}$ and $\mathrm{P}_{20} \mathrm{~A}_{196}$ aqueous solutions before mixing to form the PICsome. When each $\mathrm{P}_{20} \mathrm{M}_{190}$ and $\mathrm{P}_{20} \mathrm{~A}_{196}$ solution was prepared at $C_{\mathrm{p}}=1 \mathrm{~g} / \mathrm{L}$, the $R_{\mathrm{h}}$ value for the PICsome was ca. $100 \mathrm{~nm}$. In contrast, when each aqueous $\mathrm{P}_{20} \mathrm{M}_{190}$ and $\mathrm{P}_{20} \mathrm{~A}_{196}$ solution was prepared at $C_{\mathrm{p}}=0.01 \mathrm{~g} / \mathrm{L}$, the $R_{\mathrm{h}}$ value for the PICsome was ca. $38 \mathrm{~nm}$. The size of the PICsomes could be controlled by adjusting 
the $C_{\mathrm{p}}$ values of oppositely charged diblock copolymer solutions before mixing. When $0.1 \mathrm{M} \mathrm{NaCl}$ PICsome solutions were diluted with $0.1 \mathrm{M} \mathrm{NaCl}$, the $R_{\mathrm{h}}$ values for the PICsome remained nearly constant, independent of $C_{\mathrm{p}}$. These findings suggest that the structure of the PICsome, once prepared, is stable against dilution. In general, sonication and extrusion techniques are used to control the size of vesicles [37]. However, the easily adjustable size of the stable PICsome system described here indicates that the size of vesicles and polymersomes can be easily controlled by adjusting the $C_{\mathrm{p}}$ before mixing a pair of oppositely charged diblock copolymers.

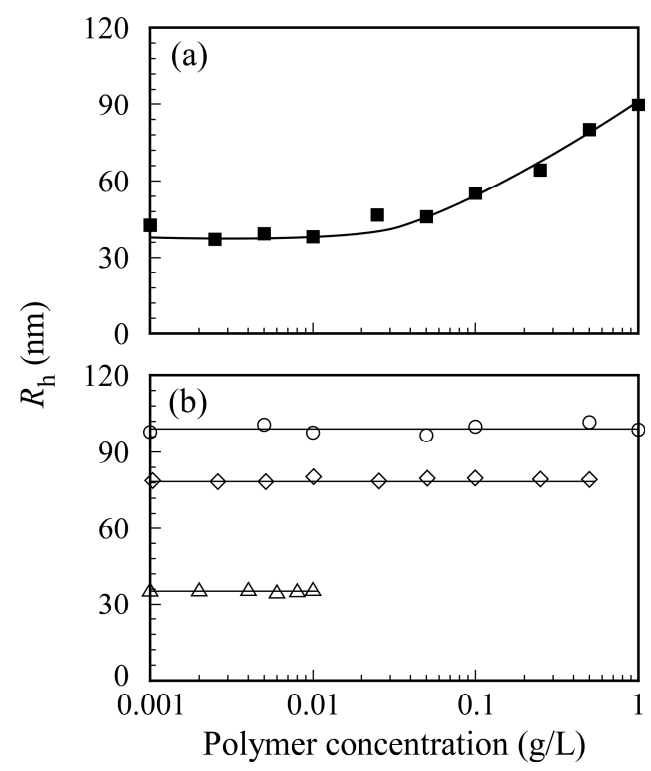

Figure 9. (a) Hydrodynamic radius $\left(R_{\mathrm{h}}\right)$ for PICsomes with $f^{+}=0.5$ as a function of polymer concentration of $\mathrm{P}_{20} \mathrm{M}_{190}$ and $\mathrm{P}_{20} \mathrm{~A}_{196}$ before mixing both block copolymers in $0.1 \mathrm{M} \mathrm{NaCl}$; (b) $R_{\mathrm{h}}$ for PICsomes with $f^{+}=0.5$ as a function of polymer concentration after mixing $\mathrm{P}_{20} \mathrm{M}_{190}$ and $\mathrm{P}_{20} \mathrm{~A}_{196}$. The aq. PICsome solutions at $1(\bigcirc), 0.5(\diamond)$, and $0.01 \mathrm{~g} / \mathrm{L}(\triangle)$ were diluted with $0.1 \mathrm{M} \mathrm{NaCl}$ continuously.

To confirm the ability to incorporate hydrophilic guest molecules into the interior aqueous phase of PICsomes, fluorescence experiments were performed using Texas red-labeled Dex as a fluorescence probe. The hydrophilic Dex molecule contains no charged groups. The $\mathrm{P}_{20} \mathrm{M}_{190}$ and $\mathrm{P}_{20} \mathrm{~A}_{196}$ were dissolved in Dex-containing PBS buffer solutions, and then these solutions were mixed to form PICsomes. The Dex molecules that could not be incorporated into the PICsomes were removed by dialysis against fresh PBS buffer for $18 \mathrm{~h}$. Fluorescence spectra were obtained for the solution inside the dialyzer after dialysis (Figure 10). Fluorescence emission with a maximum wavelength at $610 \mathrm{~nm}$ for Dex was observed, which indicates that the Dex molecules were incorporated into the hollow core of PICsome. In contrast, a blank solution in the absence of PICsomes produced no fluorescence from Dex because the small Dex molecules were removed when using a dialysis membrane with a pore size of $100 \mathrm{~nm}$. These results demonstrate that PICsomes can incorporate Dex guest molecules into the hollow core. The weight of the Dex incorporated into the PICsomes was calculated using a calibration curve, and was $0.00315 \mathrm{mg}$. The LE and LC values determined using the encapsulated Dex weight were $78.8 \%$ and $1.58 \%$, respectively. 


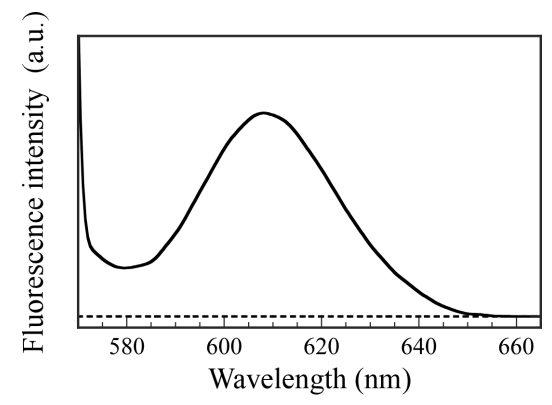

Figure 10. Fluorescence emission spectra for Dex after dialysis against PBS buffer for $18 \mathrm{~h}$ excited at $550 \mathrm{~nm}$ in the presence (--) and absence (---) of PICsomes in PBS buffer solutions.

\section{Conclusions}

A pair of oppositely charged diblock copolymers with well-controlled structures, $\mathrm{P}_{20} \mathrm{M}_{190}$ and $\mathrm{P}_{20} \mathrm{~A}_{196}$, were prepared via RAFT using PMPC macro-CTA. Polyion complex vesicles (PICsomes) were formed by stoichiometric charge neutralization of a mixture of aqueous $\mathrm{P}_{20} \mathrm{M}_{190}$ and $\mathrm{P}_{20} \mathrm{~A}_{196}$ solutions. The surface of the PICsomes was covered with biocompatible PMPC shell chains. These PICsomes could incorporate water-soluble guest molecules without charge groups inside the interior aqueous phase, which indicates that these PICsomes may be useful as a molecular carrier of several bioactive compounds.

Acknowledgments: This work was financially supported by a Grant-in-Aid for Scientific Research (25288101 and 16K14008) from the Japan Society for the Promotion of Science (JSPS), JSPS Bilateral Joint Research Projects, and the Cooperative Research Program of "Network Joint Research Center for Materials and Devices".

Author Contributions: Keita Nakai was a research student who performed the experimental work. Shin-ichi Yusa was responsible for analyzing the experimental data and writing the paper. Kazuhiko Ishihara, Michael Kappl, Syuji Fujii, and Yoshinobu Nakamura directed this research. All authors approved the manuscript.

Conflicts of Interest: The authors declare no conflict of interest.

\section{References}

1. Zhang, L.; Eisenberg, A. Multiple Morphologies of "crew-cut" aggregates of polystyrene- $b$-poly(acrylic acid) block copolymers. Science 1995, 268, 1728-1731. [CrossRef] [PubMed]

2. Discher, B.M.; Won, Y.; Ege, D.S.; Lee, J.C.M.; Bates, F.S.; Disher, D.E.; Hammer, D.A. Polymersomes: Tough vesicles made from diblock copolymers. Science 1999, 284, 1143-1146. [CrossRef] [PubMed]

3. Kita-Tokarczyk, K.; Grumelard, J.; Haefele, T.; Meier, W. Block copolymer vesicles-using concepts from polymer chemistry to mimic biomembranes. Polymer 2005, 46, 3540-3563. [CrossRef]

4. Soo, P.L.; Eisenberg, A. Preparation of block copolymer vesicles in solution. J. Polym. Sci. Polym. Phys. 2004, 42, 923-938.

5. Kukula, H.; Schlaad, H.; Antonietti, M.; Förster, S. The formation of polymer vesicles or "peptosomes" by polybutadiene-block-poly(L-glutamate)s in dilute aqueous solution. J. Am. Chem. Soc. 2002, 124, 1658-1663. [CrossRef] [PubMed]

6. Wittemann, A.; Azzam, T.; Eisenberg, A. Biocompatible polymer vesicles from biamphiphilic triblock copolymers and their interaction with bovine serum albumin. Langmuir 2007, 23, 2224-2230. [CrossRef] [PubMed]

7. Kishimura, A.; Liamsuwan, S.; Matsuda, H.; Dong, W.F;; Osada, K.; Yamasaki, Y.; Kataoka, K. pH-dependent permeability change and reversible structural transition of PEGylated polyion complex vesicles (PICsomes) in aqueous media. Soft Matter 2009, 5, 529-532. [CrossRef]

8. Stuart, M.A.C.; Besseling, N.A.M.; Fokkink, R.G. Formation of micelles with complex coacervate cores. Langmuir 1998, 14, 6846-6849. [CrossRef]

9. Hofs, B.; de Keizer, A.; Stuart, M.A.C. On the stability of (highly aggregated) polyelectrolyte complexes containing a charged-block-neutral diblock copolymer. J. Phys. Chem. B 2007, 111, 5621-5627. [CrossRef] [PubMed] 
10. Schrage, S.; Sigel, R.; Helmut Schlaad, H. Formation of amphiphilic polyion complex vesicles from mixtures of oppositely charged block ionomers. Macromolecules 2003, 36, 1417-1420. [CrossRef]

11. Yusa, S.; Yokoyama, Y.; Morishima, Y. Synthesis of oppositely charged block copolymers of poly(ethylene glycol) via reversible addition-fragmentation chain transfer radical polymerization and characterization of their polyion complex micelles in water. Macromolecules 2009, 42, 376-383. [CrossRef]

12. Nakai, K.; Nishiuchi, M.; Inoue, M.; Ishihara, K.; Sanada, Y.; Sakurai, K.; Yusa, S. Preparation and characterization of polyion complex micelles with phosphobetaine shells. Langmuir 2013, 29, 9651-9661. [CrossRef] [PubMed]

13. Iwasaki, Y.; Ijuin, M.; Mikami, A.; Nakabayashi, N.; Ishihara, K. Behavior of blood cells in contact with water-soluble phospholipid polymer. J. Biomed. Mater. Res. 1999, 6, 360-367. [CrossRef]

14. Walther, A.; Goldmann, A.S.; Yelamanchili, R.S.; Drechsler, M.; Schmalz, H.; Eisenberg, A.; Müller, A.H.E. Multiple morphologies, phase transitions, and cross-linking of crew-cut aggregates of polybutadiene-block-poly(2-vinylpyridine) diblock copolymers. Macromolecules 2008, 41, 3254-3260. [CrossRef]

15. Huang, J.; Bonduelle, C.; Thévenot, J.; Lecommandoux, S.; Heise, A. Biologically active polymersomes from amphiphilic glycopeptides. J. Am. Chem. Soc. 2012, 134, 119-122. [CrossRef] [PubMed]

16. Ishihara, K.; Ueda, T.; Nakabayashi, N. Preparation of phospholipid polymers and their properties as polymer hydrogel membranes. Polym. J. 1990, 22, 355-360. [CrossRef]

17. Mitsukami, Y.; Donovan, M.S.; Lowe, A.B.; McCormick, C.L. Water-soluble polymers. 81. Direct synthesis of hydrophilic styrenic-based homopolymers and block copolymers in aqueous solution via RAFT. Macromolecules 2001, 34, 2248-2256.

18. Yusa, S.; Fukuda, K.; Yamamoto, T.; Ishihara, K.; Morishima, Y. Synthesis of well-defined amphiphilic block copolymers having phospholipid polymer sequences as a novel biocompatible polymer micelle reagent. Biomacromolecules 2005, 6, 663-670. [CrossRef] [PubMed]

19. Nicolai, T.; Brown, W.; Johnsen, R.M.; Stepanek, P. Dynamic behavior of $\theta$ solutions of polystyrene investigated by dynamic light scattering. Macromolecules 1990, 23, 1165-1174. [CrossRef]

20. Jakeš, J. Testing of the constrained regularization method of inverting Laplace transform on simulated very wide quasielastic light scattering autocorrelation functions. Czechoslov. J. Phys. B. 1988, 38, 1305-1316. [CrossRef]

21. Harding, S.E.; Sattelle, D.B.; Bloomfield, V.A. Laser Light Scattering in Biochemistry; The Royal Society of Chemistry: Cambridge, UK, 1992; p. 81.

22. Stockmayer, W.H.; Schmidt, M. Effects of polydispersity, branching and chain stiffness on quasielastic light scattering. Pure Appl. Chem. 1982, 54, 407-414. [CrossRef]

23. Ali, S.I.; Heuts, J.P.A.; van Herk, A.M. Controlled synthesis of polymeric nanocapsules by RAFT-based vesicle templating. Langmuir 2010, 26, 7848-7858. [CrossRef] [PubMed]

24. Berret, J.-F. Controlling electrostatic co-assembly using ion-containing copolymers: From surfactants to nanoparticles. Adv. Colloid Interface Sci. 2011, 167, 38-48. [CrossRef] [PubMed]

25. Fresnais, J.; Lavelle, C.; Berret, J.-F. Nanoparticle aggregation controlled by desalting kinetics. J. Phys. Chem. C 2009, 113, 16371-16379. [CrossRef]

26. Qi, L.; Fresnais, J.; Berret, J.-F.; Castaing, J.-C.; Grillo, I.; Chapel, J.-P. Influence of the formulation process in electrostatic assembly of nanoparticles and macromolecules in aqueous solution: The mixing pathway. J. Phys. Chem. C 2010, 114, 12870-12877. [CrossRef]

27. Goto, F.; Ishihara, K.; Iwasaki, Y.; Katayama, K.; Enomoto, R.; Yusa, S. Thermo-responsive behavior of hybrid core cross-linked polymer micelles with biocompatible shells. Polymer 2011, 52, 2810-2818. [CrossRef]

28. Xu, R.; Winnik, M.A.; Hallett, F.R.; Riess, G.; Croucher, M.D. Light-scattering study of the association behavior of styrene-ethylene oxide block copolymers in aqueous solution. Macromolecules 1991, 24, 87-93. [CrossRef]

29. Burchard, W. Static and dynamic light scattering from branched polymers and biopolymers. Adv. Polym. Sci. 1983, 48, 1-124.

30. Konishi, T.; Yoshizaki, T.; Yamakawa, H. On the "Universal Constants" $\rho$ and $\Phi$. of flexible polymers. Macromolecules 1991, 24, 5614-5622. [CrossRef]

31. Burchard, W.; Schmidt, M.; Stockmayer, W.H. Information on polydispersity and branching from combined quasi-elastic and integrated scattering. Macromolecules 1980, 13, 1265-1272. [CrossRef] 
32. Li, J.; Ping, Y. Self-assembly of ibuprofen and bovine serum albumin-dextran conjugates leading to effective loading of the drug. Langmuir 2009, 25, 6385-6391. [CrossRef] [PubMed]

33. Burger, C.; Hao, J.; Ying, Q.; Isobe, H.; Sawamura, M.; Nakamura, E.; Chu, B. Multilayer vesicles and vesicle clusters formed by the fullerene-based surfactant $\mathrm{C}_{60}\left(\mathrm{CH}_{3}\right)_{5} \mathrm{~K}$. J. Colloid Interface Sci. 2004, 275, 632-641. [CrossRef] [PubMed]

34. Mousseau, F.; Vitorazi, L.; Herrmann, L.; Mornet, S.; Berret, J.-F. Polyelectrolyte assisted charge titration spectrometry: Applications to latex and oxide nanoparticles. J. Colloid Interface Sci. 2016, 475, 36-45. [CrossRef] [PubMed]

35. Discher, D.E.; Ahmed, F. Polymersomes. Annu. Rev. Biomed. Eng. 2006, 8, 323-341. [CrossRef] [PubMed]

36. Anraku, Y.; Kishimura, A.; Yamasaki, Y.; Kataoka, K. Living Unimodal growth of polyion complex vesicles via two-dimensional supramolecular polymerization. J. Am. Chem. Soc. 2013, 135, 1423-1429. [CrossRef] [PubMed]

37. Lapinski, M.M.; Castro-Forero, A.; Greiner, A.J.; Ofoli, R.Y.; Blanchard, G.J. Comparison of liposomes formed by sonication and extrusion: Rotational and translational diffusion of an embedded chromophore. Langmuir 2007, 23, 11677-11683. [CrossRef] [PubMed]

(C) 2017 by the authors; licensee MDPI, Basel, Switzerland. This article is an open access article distributed under the terms and conditions of the Creative Commons Attribution (CC BY) license (http:/ / creativecommons.org/licenses/by/4.0/). 